\title{
Carinal and tubular airway particle concentrations in the large airways of non-smokers in the general population: evidence for high particle concentration at airway carinas
}

\author{
A Churg, S Vedal
}

\begin{abstract}
Objective-To evaluate the extent to which human airway carinas accumulate ambient atmospheric particles, a newly developed technique was used to microdissect and analyse particle concentration in tubular segments and carinas of the large airways of 10 necropsy lungs from non-smokers from the general population of Vancouver.
\end{abstract}

Methods-Ratios of the particle concentrations on the carinas to the tubular segment immediately preceding it were measured with analytical electron microscopy for the mainstem bronchus, upper and lower lobe bronchi, and four different segmental or subsegmental bronchi-that is, Weibel generations 1 to about 5. A total of 119 carinal-tubular pairs was evaluated.

Results-Over all cases, both carinal and tubular particle concentrations increased with increasing airway generation; the median ratio of carinal to tubular particle concentration was 9:1 and did not show any trend with airway generation. The ratio was $>5$ in $71 \%$ of carinal-tubular pairs, $>10$ in $42 \%$ of pairs, $>20$ in $31 \%$ of pairs, and $>100$ in $9 \%$ of pairs. Some subjects showed a notable tendency to high ratios, with many ratios $>100$, and other subjects had a tendency toward low ratios. The predominant mineral species in both carinas and tubular airway segments was crystalline silica and the relative proportion was similar in both sites; however, mean particle diameter was consistently less in the carinal tissues.

Conclusions-These findings suggest that the ratio of carinal to tubular retained particles in the large airways in nonsmokers is higher than might be supposed from data generated in airway casts, and that there is considerable variation in this ratio between subjects. This finding is of potential interest in models of carcinogen, toxin, and dose of fibrogenic agent to the large airways as it suggests high and sometimes extreme concentrations of toxic particles at carinas, and thus reinforces the notion that carinas may be sites of initiation of disease.

(Occup Environ Med 1996;53:553-558)

Keywords: airways; carinas; cigarette smoke; radiation
Understanding particle deposition and retention is important to understanding the effects of ambient air pollutants and contaminants on the lung, and in explaining the pathogenesis of certain diseases. Knowledge of particle deposition and clearance may be important in explaining why only some patients develop particle related diseases, and why certain diseases occur in specific anatomical regions of the lung. Attention has recently been redirected to the importance of ambient atmospheric particulate pollution by findings linking pulmonary morbidity and mortality with the inhalable particulate fraction of air pollution. ${ }^{1}$

Studies from several different laboratories have confirmed that everyone in the population carries a numerically large burden of inhaled ambient mineral particles in the lung parenchyma (typically $10^{7}$ to $10^{8}$ particles $/ g$ dry lung),,$^{2-5}$ and studies from our laboratory ${ }^{67}$ have shown that the mucosa of large airways also accumulates substantial numbers of atmospheric particles.

Carinas (the actual ridge dividing airways) and bifurcation zones (the area around the carinal ridge) are sites of particular interest in deposition models and toxicology studies. Enhanced particle deposition at carinas and bifurcations in the large airways is thought to occur because of impaction of larger particles at high rates of flow and because of diffusional deposition of particles of $<1 \mu .^{8}$ Enhanced deposition or retention has been found in animal models, ${ }^{9-11}$ and it seems from such models that some fibrotic processes induced by dust in the lung start at small airway carinas. ${ }^{10}$ Depositional concentration of chemical carcinogens or radioactive particles at bifurcations has been postulated to play a major part in human pulmonary carcinogenesis, ${ }^{812-15}$ and this process may be augmented by poor clearance of particles from carinal ridges. ${ }^{911}$

Information about the degree to which human airway bifurcations do actually concentrate particles is extremely limited. Little et al ${ }^{12}$ reported mean polonium-210 $\left({ }^{210} \mathrm{Po}\right)$ ratios (obtained by bulk tissue digestion) of about 5:1 to $10: 1$ between lobar bronchi and bifurcations in necropsy lungs of cigarette smokers; however, Henshaw et al ${ }^{16}$ found no evidence and Cohen et al ${ }^{17}$ only marginally significant evidence, with autoradiography, for concentrations of radioactive smoke particles at human airway carinas.

Although enhanced deposition has been shown in human airway casts and models, ${ }^{8131517-20}$ (see discussion) to our knowledge

Mall, Vancouver, BC

V6T 2B5, Canada.

Accepted 21 February 1996 
there are no data concerning particle concentrations at bifurcation regions and carinas in actual human lungs, nor is there information about differences in concentrations of carinal particles in different portions of the lung or differences in accumulation of carinal particles from subject to subject. We have developed a method for microdissecting human airway mucosa and then extracting and measuring particles by analytical electron microscopy. This approach makes use of the fact that some proportion of particles landing on an airway surface are translocated through the epithelium to the subepithelial tissues, ${ }^{9}$ from which location they are removed slowly or not at all. Thus measurement of particles in airway mucosa provides both an indication of density of particles landing on the epithelium and of long term particle retention. In previous studies $^{67}$ we have used this technique to evaluate particles in tubular airway segments and shown that the patterns of particle concentration match those expected from mathematical models of particle deposition (see discussion). Here we extend our findings to report on relative particle concentration in the carinas compared with the tubular segments of large airways in lifetime non-smokers.

\section{Materials and methods}

CASE SELECTION

Lungs from a general necropsy service were used for this study. Smoking, residential, and occupational histories were obtained by interviews with relatives. All patients in this report had been lifetime non-smokers, and none had had occupational dust exposure (the questionnaire used specifically covered exposure to asbestos, non-asbestos insulating materials, sawmill work, any kind of mining, sand blasting, and grain handling). All had lived in Vancouver for at least 20 years. There were six women and four men; the mean (SD) age was 80 (12) with a range of 65 to 98 . None of the patients had died of lung disease. The 10 lungs analysed were all morphologically normal at necropsy except for the presence of minor degrees of pneumonia.

\section{DISSECTION PROCEDURE}

Only left lungs were used. For each specimen the airways were opened starting at the hilus from the medial side. Following the bronchial pathways described below, mucosa from tubular segments of airways was obtained by dissecting the mucosa (defined as all tissues between the lumen and the cartilage) off the underlying cartilage as previously described. ${ }^{67}$ Mucosa from the whole circumference of the airway was used; the linear length of mucosa dissected was usually $0.5 \mathrm{~cm}$ except in regions where successive carinas were so closely spaced that shorter tubular mucosal segments had to be used.

Following along the airway, the mucosa of the next succeeding carinal ridge was then dissected free of its cartilage with an ophthalmic surgical knife and a dissecting microscope. To provide as consistent results as possible, an attempt was made to obtain only carinal ridge tissue, which was arbitrarily defined as tissue within about $0.1 \mathrm{~cm}$ on either side of the ridge. Dissection was continued until the airways became so narrow that the carinal ridge length dropped below about $0.3 \mathrm{~cm}$ (where even microdissection of the ridge mucosa becomes extremely difficult), which, depending on case and specific airway, was in generation 3 to 5 .

The following airways were examined for each case:

the mainstem bronchus and carina separating upper and lower lobe;

upper lobe bronchus;

apical posterior segmental bronchus of the upper lobe;

anterior segmental bronchus of the upper lobe; lower lobe bronchus;

superior segmental bronchus of the lower lobe; posterior basal bronchus of the lower lobe.

TISSUE DISSOLUTION AND PARTICLE COUNTING Tissue samples were dried to constant weight, after which both tubular airway segments and carinal ridge mucosal samples were dissolved in bleach and the mineral particles collected on Millipore filters; samples were then transferred to coated electron microscope grids as previously described. ${ }^{67}$ The samples were examined in an electron microscope equipped with an energy dispersive $x$ ray spectrometer. For each sample about 20 particles were counted, measured, and identified by a combination of morphology and chemistry by $x$ ray spectroscopy, supplemented by electron diffraction in some instances. For some sites it was not possible to find 20 particles in any reasonable counting time. Numbers of particles/g dry tissue were calculated with an algorithm relating weight of tissue used and numbers of squares of the electron microscope grid counted.

Blank samples in which the entire method was run without tissue were prepared for every specimen to ensure that we were not counting contaminants from the preparative procedure. These blanks showed 0 to 2 (generally 0 ) particles with exactly the same counting conditions as used for the actual samples; where particles were encountered in the blanks, the equivalent number was subtracted from the specimen count.

\section{STATISTICAL ANALYSIS}

All analyses involving tubular and carinal particle concentrations were performed on log transformed values. As particle concentrations were measured at several sites within each subject's airways, a repeated measures analysis was performed. Except for the mainstem bronchus (generation 1), in which only one site was sampled, for the other airways up to four sites were sampled. The first step in the analysis was to measure whether there was significant variability in concentrations between sites within each generation. If no significant variation between sites was present, then a generation concentration could be calculated as the mean of the site concentrations for each 
Table 1 Log airway concentrations by bronchial site and generation for all subjects (mean (SD)) at carinal and tubular locations (logs based on particle concentration $\times 10^{-6} / g$ dry tissue)

\begin{tabular}{|c|c|c|c|c|c|c|c|c|c|}
\hline \multicolumn{5}{|c|}{ Tubular segments } & \multicolumn{5}{|c|}{ Carinas } \\
\hline \multicolumn{2}{|c|}{ Generation } & \multicolumn{3}{|l|}{ Site } & \multicolumn{2}{|c|}{ Generation } & \multicolumn{3}{|l|}{ Site } \\
\hline 1 & & $\begin{array}{l}\text { Left main } \\
2.60(0.97)\end{array}$ & & & 1 & & $\begin{array}{l}\text { Left main } \\
5.39(1 \cdot 27)\end{array}$ & & \\
\hline $\begin{array}{l}\text { L } \\
3\end{array}$ & $\begin{array}{l}\text { Lower lobe } \\
3.42(1.09)\end{array}$ & & $\begin{array}{l}\text { Upper lobe } \\
3.45(0.78)\end{array}$ & & 2 & $\begin{array}{l}\text { Lower lobe } \\
5 \cdot 40(1 \cdot 75)\end{array}$ & & $\begin{array}{l}\text { Upper lobe } \\
5.88(0.99)\end{array}$ & \\
\hline $\begin{array}{l}3 \\
4\end{array}$ & $\begin{array}{l}\text { PB } \\
3.97(1 \cdot 21) \\
4.41(1 \cdot 16)\end{array}$ & $\begin{array}{l}\text { SS } \\
3.44(1.09) \\
4.06(1.26)\end{array}$ & $\begin{array}{l}\text { AP } \\
3.89(0.83) \\
4.17(1.01)\end{array}$ & $\begin{array}{l}\text { AS } \\
4.06(0.93) \\
4.75(0.95)\end{array}$ & $\begin{array}{l}3 \\
4\end{array}$ & $\begin{array}{l}\text { PB } \\
6.14(2.09) \\
6.13(1.35)\end{array}$ & $\begin{array}{l}\text { SS } \\
5.11(1.51) \\
6.03(1.61)\end{array}$ & $\begin{array}{l}\text { AP } \\
6.50(1.61) \\
6.94(1.36)\end{array}$ & $\begin{array}{l}\text { AS } \\
6.53(1.04) \\
7.41(1.34)\end{array}$ \\
\hline
\end{tabular}

There were no significant $(P<0.05)$ differences in concentrations between sites within each generation for either tubular or carinal concentrations.

PB = posterior basal segment lower lobe; SS = superior segment lower lobe; $A P$ = apical-posterior segment upper lobe; AS $=$ anterior segment upper lobe.

Table 2 Log tubular and carinal particle concentrations by airway generation for each subject (logs based on particle concentration $\times 10^{-6} / \mathrm{gm}$ dry tissue)

\begin{tabular}{|c|c|c|c|c|c|c|c|c|}
\hline \multirow[b]{2}{*}{ Subject } & \multicolumn{4}{|c|}{ Tubular segments, airway generation } & \multicolumn{4}{|c|}{ Carinas, airway generation } \\
\hline & 1 & 2 & 3 & 4 & 1 & 2 & 3 & 4 \\
\hline $\begin{array}{l}1 \\
2 \\
3 \\
4 \\
5 \\
6 \\
7 \\
8 \\
9 \\
10 \\
\text { Mean* (SD) } \\
\text { Geometric mean }\end{array}$ & $\begin{array}{l}3 \cdot 14 \\
1.63 \\
1.53 \\
1 \cdot 77 \\
3 \cdot 87 \\
3.74 \\
3.81 \\
2.40 \\
2.48 \\
1.65 \\
2 \cdot 60 \\
(0 \cdot 97) \\
14\end{array}$ & $\begin{array}{l}3 \cdot 22 \\
3 \cdot 65 \\
2 \cdot 95 \\
1 \cdot 81 \\
4 \cdot 59 \\
3 \cdot 60 \\
4 \cdot 64 \\
3 \cdot 55 \\
2 \cdot 83 \\
3 \cdot 50 \\
3 \cdot 43 \\
(0 \cdot 83) \\
31\end{array}$ & $\begin{array}{l}3 \cdot 65 \\
4 \cdot 40 \\
3 \cdot 16 \\
2 \cdot 37 \\
4 \cdot 82 \\
4 \cdot 84 \\
4 \cdot 92 \\
3 \cdot 70 \\
2 \cdot 99 \\
3 \cdot 34 \\
3 \cdot 82 \\
(0 \cdot 89) \\
46\end{array}$ & $\begin{array}{l}3 \cdot 80 \\
4 \cdot 99 \\
4 \cdot 04 \\
3 \cdot 24 \\
5 \cdot 15 \\
5 \cdot 01 \\
5 \cdot 46 \\
3 \cdot 60 \\
3 \cdot 61 \\
4 \cdot 08 \\
4 \cdot 30 \\
(0 \cdot 78)\end{array}$ & $\begin{array}{l}4 \cdot 87 \\
3 \cdot 09 \\
4 \cdot 77 \\
5 \cdot 14 \\
7 \cdot 17 \\
6 \cdot 35 \\
6 \cdot 96 \\
6 \cdot 33 \\
4 \cdot 62 \\
4 \cdot 62 \\
5 \cdot 39 \\
(1 \cdot 27) \\
219\end{array}$ & $\begin{array}{l}5 \cdot 96 \\
6 \cdot 57 \\
4 \cdot 82 \\
4 \cdot 27 \\
6 \cdot 67 \\
7 \cdot 83 \\
6 \cdot 14 \\
5 \cdot 25 \\
4 \cdot 47 \\
4 \cdot 39 \\
5 \cdot 64 \\
(1 \cdot 19) \\
281\end{array}$ & $\begin{array}{l}5 \cdot 42 \\
6 \cdot 13 \\
4 \cdot 90 \\
7 \cdot 36 \\
6 \cdot 73 \\
8 \cdot 18 \\
6 \cdot 67 \\
5 \cdot 35 \\
5 \cdot 23 \\
4 \cdot 43 \\
6 \cdot 04 \\
(1 \cdot 18) \\
420\end{array}$ & $\begin{array}{l}5 \cdot 98 \\
6 \cdot 22 \\
5 \cdot 09 \\
8 \cdot 08 \\
7 \cdot 22 \\
7 \cdot 36 \\
6 \cdot 89 \\
5 \cdot 76 \\
7 \cdot 26 \\
4 \cdot 86 \\
6 \cdot 48 \\
(1 \cdot 06) \\
651\end{array}$ \\
\hline
\end{tabular}

${ }^{\star} P=0.002$ for difference between generations for tubular concentrations;

$P=0.195$ for difference between generations for carinal concentrations;

$P<0.001$ for difference between tubular and carinal concentrations;

$\mathbf{P}=0.651$ for difference in carinal:tubular ratio between generation.

generation. A multivariate two way repeated measures analysis of variance was then performed to test for generational concentration differences, for differences between carinal and tubular concentration, and for variation in the carinal-tubular differences found by generation. Analyses were performed with the GLIM procedure in SAS. ${ }^{20}$ For comparison of particle sizes in carinas and tubular segments, $t$ tests were used.

\section{Results}

Carinal and tubular particle concentrations were measured in 119 paired carinal-tubular samples from the 10 subjects. Table 1 shows
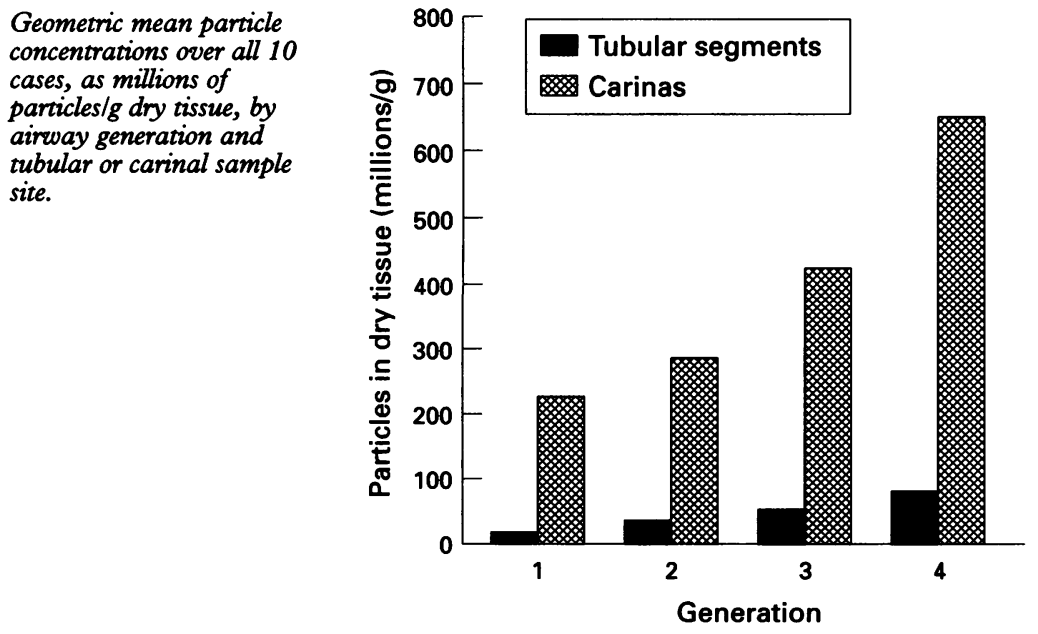

the mean log tubular and carinal particle concentration at each site by generation for generations 1 to 4 . Because only a few generation 5 sites had been sampled, these were excluded from all calculations. As there were no significant differences in either carinal or tubular particle concentrations between sites, sites were averaged within each generation to obtain a single concentration for each generation. There was a significant difference in tubular particle concentration from generations 1 to 4 , with tubular concentrations increasing with increasing generation (table 2). Carinal particle concentrations also tended to increase with increasing generation, but because of the greater variability in carinal concentrations within subjects (table 2), this was not significant ( $P=0 \cdot 195)$.

Table 2 also shows the degree of particle concentration variability between people. For example, for tubular concentrations in generation 1 there was a 10 -fold difference in raw (non-logged) concentrations between people; for carinal concentrations there was a 60 -fold difference.

Concentrations of particles were significantly lower in the tubular than carinal regions in each generation (table 2 and figure). No significant interaction between the carinal-tubular difference (on a log scale) and generation was present, implying that the proportion of carinal to tubular concentrations did not vary by generation (figure). Over all 119 pairs the median carinal to tubular particle concentration ratio was $9: 1$. The ratio was $>5$ in $71 \%$ of 
Table 3 Distribution of mineral species in carinas and tubular segments as \% of total particles

\begin{tabular}{|c|c|c|c|c|c|c|c|}
\hline Case & Silica & Iron & Kaolin & Talc & Mica & Metals* & Miscellaneous \\
\hline \multicolumn{8}{|l|}{ 1: } \\
\hline Carinal & $42 \cdot 1$ & $12 \cdot 6$ & $15 \cdot 8$ & $15 \cdot 8$ & $3 \cdot 3$ & $7 \cdot 0$ & $3 \cdot 3$ \\
\hline Tubular & $64 \cdot 4$ & $3 \cdot 6$ & $5 \cdot 4$ & $15 \cdot 4$ & 3.5 & $4 \cdot 9$ & $2 \cdot 9$ \\
\hline \multicolumn{8}{|l|}{ 2: } \\
\hline Carinal & $82 \cdot 2$ & $3 \cdot 4$ & $2 \cdot 3$ & $8 \cdot 9$ & 0 & $1 \cdot 4$ & 1.7 \\
\hline \multirow{2}{*}{\multicolumn{8}{|c|}{ 3: }} \\
\hline & & & & & & & \\
\hline Carinal & $96 \cdot 1$ & 0.5 & $1 \cdot 1$ & $0 \cdot 7$ & $0 \cdot 1$ & $0 \cdot 3$ & $1 \cdot 3$ \\
\hline Tubular & $89 \cdot 2$ & $2 \cdot 0$ & $2 \cdot 0$ & $2 \cdot 8$ & $0 \cdot 7$ & $0 \cdot 7$ & $1 \cdot 8$ \\
\hline \multicolumn{8}{|l|}{$4:$} \\
\hline Carinal & $67 \cdot 8$ & $6 \cdot 5$ & $3 \cdot 6$ & $14 \cdot 1$ & 0.6 & $4 \cdot 2$ & $2 \cdot 9$ \\
\hline Tubular & $57 \cdot 8$ & $6 \cdot 3$ & $7 \cdot 0$ & $13 \cdot 2$ & $5 \cdot 6$ & $9 \cdot 7$ & $2 \cdot 9$ \\
\hline \multicolumn{8}{|l|}{ 5: } \\
\hline Carinal & $69 \cdot 0$ & $9 \cdot 3$ & $6 \cdot 5$ & $5 \cdot 4$ & $3 \cdot 2$ & $2 \cdot 1$ & $4 \cdot 6$ \\
\hline Tubular & $65 \cdot 0$ & $13 \cdot 6$ & $3 \cdot 9$ & $8 \cdot 0$ & $1 \cdot 1$ & $2 \cdot 7$ & $5 \cdot 7$ \\
\hline \multicolumn{8}{|l|}{ 6: } \\
\hline Carinal & $82 \cdot 4$ & $5 \cdot 6$ & $1 \cdot 4$ & $7 \cdot 8$ & 0 & $1 \cdot 1$ & $1 \cdot 7$ \\
\hline \multirow{2}{*}{\multicolumn{8}{|c|}{$7:$}} \\
\hline & & & & & & & \\
\hline Carinal & $77 \cdot 4$ & $5 \cdot 9$ & $5 \cdot 8$ & $0 \cdot 6$ & $1 \cdot 7$ & $2 \cdot 5$ & $6 \cdot 1$ \\
\hline Tubular & $69 \cdot 8$ & $9 \cdot 2$ & $4 \cdot 5$ & $4 \cdot 6$ & $2 \cdot 8$ & 1.6 & $7 \cdot 5$ \\
\hline \multicolumn{8}{|l|}{ 8: } \\
\hline Carinal & $47 \cdot 1$ & $22 \cdot 1$ & $10 \cdot 7$ & $4 \cdot 4$ & $0 \cdot 5$ & $5 \cdot 2$ & $9 \cdot 9$ \\
\hline Tubular & $59 \cdot 1$ & $13 \cdot 8$ & $10 \cdot 7$ & $3 \cdot 6$ & $2 \cdot 7$ & $4 \cdot 5$ & $5 \cdot 6$ \\
\hline \multicolumn{8}{|l|}{$9:$} \\
\hline Carinal & $60 \cdot 2$ & $1 \cdot 6$ & 16.9 & $4 \cdot 9$ & $4 \cdot 3$ & $4 \cdot 0$ & $8 \cdot 0$ \\
\hline Tubular & $67 \cdot 2$ & $6 \cdot 8$ & $6 \cdot 5$ & $3 \cdot 7$ & $5 \cdot 4$ & $2 \cdot 9$ & $7 \cdot 5$ \\
\hline \multicolumn{8}{|l|}{ 10: } \\
\hline Carinal & $27 \cdot 9$ & $4 \cdot 3$ & $45 \cdot 0$ & $0 \cdot 3$ & $1 \cdot 4$ & $14 \cdot 7$ & $6 \cdot 4$ \\
\hline Tubular & 42.5 & $8 \cdot 1$ & $30 \cdot 2$ & $5 \cdot 6$ & $2 \cdot 8$ & $8 \cdot 0$ & $2 \cdot 7$ \\
\hline
\end{tabular}

${ }^{\star}$ Metals $=$ particles analysed as aluminum or titanium, presumably aluminum oxide and titanium dioxide.

Table 4 Geometric mean particle size by case and tubular or carinal samples

\begin{tabular}{|c|c|c|}
\hline Case & Geometric mean (GSD, $\mu$ ) & Pvalue \\
\hline \multicolumn{3}{|l|}{ 1: } \\
\hline Carinal & $0 \cdot 81(2 \cdot 2)$ & \multirow[t]{2}{*}{ NS } \\
\hline Tubular & $0.83(2 \cdot 2)$ & \\
\hline \multicolumn{3}{|l|}{ 2: } \\
\hline Carinal & $1 \cdot 00(2 \cdot 7)$ & \multirow[t]{2}{*}{$<0.02$} \\
\hline Tubular & $1 \cdot 23(2 \cdot 2)$ & \\
\hline \multicolumn{3}{|l|}{ 3: } \\
\hline Carinal & $0 \cdot 60(2 \cdot 2)$ & \multirow[t]{3}{*}{$<0.001$} \\
\hline Tubular & $0 \cdot 78(2 \cdot 1)$ & \\
\hline \multicolumn{2}{|l|}{ 4: } & \\
\hline Carinal & $0.93(2 \cdot 2)$ & \multirow[t]{2}{*}{$<0.02$} \\
\hline Tubular & $1 \cdot 12(2 \cdot 4)$ & \\
\hline \multicolumn{3}{|l|}{$5:$} \\
\hline Carinal & $0.61(2 \cdot 4)$ & \multirow{3}{*}{$<0.02$} \\
\hline Tubular & $0.75(2 \cdot 6)$ & \\
\hline \multicolumn{2}{|l|}{ 6: } & \\
\hline Carinal & $0 \cdot 78(2 \cdot 8)$ & \multirow[t]{2}{*}{$<0.003$} \\
\hline Tubular & $1.03(2 \cdot 7)$ & \\
\hline \multicolumn{3}{|l|}{$7:$} \\
\hline Carinal & $0.95(2.9)$ & \multirow[t]{2}{*}{$<0.001$} \\
\hline Tubular & $1 \cdot 33(2 \cdot 8)$ & \\
\hline \multicolumn{3}{|l|}{ 8: } \\
\hline Carinal & $0.97(2 \cdot 7)$ & \multirow[t]{2}{*}{$<0.05$} \\
\hline Tubular & $1 \cdot 19(2 \cdot 6)$ & \\
\hline \multicolumn{3}{|l|}{ 9: } \\
\hline Carinal & $0 \cdot 66(2 \cdot 2)$ & \multirow[t]{2}{*}{$<0.06$} \\
\hline Tubular & $0 \cdot 77(2 \cdot 3)$ & \\
\hline \multicolumn{3}{|l|}{ 10: } \\
\hline Carinal & $0.93(2.9)$ & \multirow[t]{2}{*}{ NS } \\
\hline Tubular & $0.96(3.0)$ & \\
\hline
\end{tabular}

Table 5 Three cases illustrating between subject variation in carinal:tubular particle concentration ratios

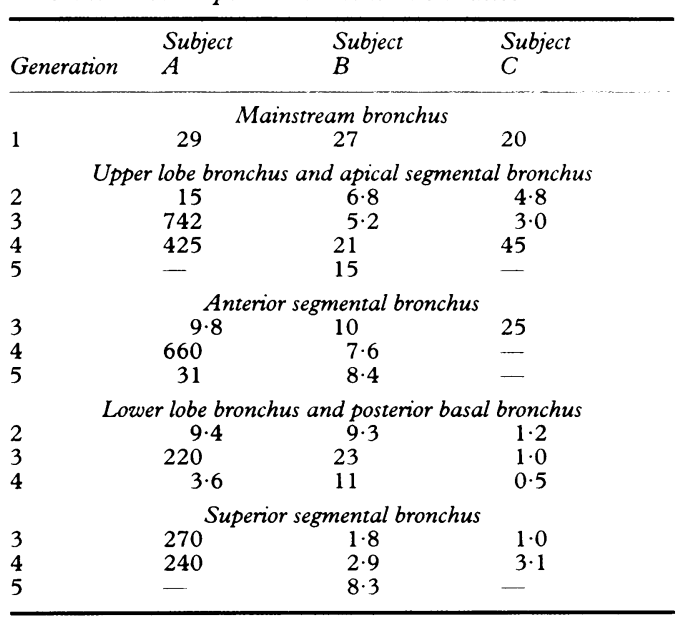

carinal:tubular pairs, $>10$ in $42 \%$ of pairs, $>20$ in $31 \%$ of pairs, and $>100$ in $9 \%$ of pairs.

Table 3 shows the types of minerals found in the tubular and carinal samples. Crystalline silica was the predominant mineral in both sites, and there were no obvious differences between carinas and tubular segments.

Table 4 shows the mean particle size in carinas and tubular segments. Geometric mean particle sizes in the carinas were smaller than in the tubular segments in every case, and the differences were significant, or nearly so, in eight of the 10 cases.

\section{Discussion}

This study extends our previous findings on the ambient atmospheric particulate load of the airway mucosa in lifelong non-smokers in the general population. ${ }^{6}$ In that study we found that particle concentration in the tubular segments of the large airways increased with increasing airway generation, increasing distance from the carina, and decreasing airway diameter. Our present results show that progressive increases in particle concentration are also found in carinal ridge mucosa in the large airways, and that the concentration of particles in the carinal mucosa is notably greater than that in the tubular segments when averaged over all cases, with a median carinal:tubular ratio of about $9: 1$. This ratio does not change significantly from generation to generation.

These results are at least qualitatively similar to those obtained from human airway casts, which also show progressively greater particle concentrations in both carinas and tubular segments with increasing airway generation. ${ }^{1718}$ The concentration ratios that we find are considerably greater than the values of about $1 \cdot 1: 1$ to $4: 1$ reported by Cohen et al ${ }^{17}$ and Hofmann and Martonen ${ }^{8}$ in airway casts, 
but considerably less than the average value of about 20:1 reported by Schlesinger and Lippmann. ${ }^{13}$ This difference may in part be a matter of the exact anatomical site analysed as, experimentally, particle deposition increases progressively as one moves from the tubular airway segment to the bifurcation zone then to the ridge itself, with a notable concentration on the ridge. ${ }^{8} \mathrm{~A}$ further complication is that relative carinal deposition varies with particle size: Bell, ${ }^{21}$ with a hollow model based on measured human anatomy and making detailed measurements, found that the relative concentration in the "hot spot" at the bifurcation ranged from $3 \cdot 35$ times for $1 \cdot 1 \mu$ particles to 25.4 times for $5.7 \mu$ particles (table 4 ). The particles we find in the airways and carinas tend toward the smaller end of this range, with the silica particles, which constitute most particles in both airways and carinas, having a mean aerodynamic diameter of about 1.3 to $2 \cdot 0 \mu$. Lastly, it should be noted that it is unclear from the scientific literature whether the cited carinal:tubular ratios have been calculated with proximal tubular segments and distal carinas, as we have done, or proximal carinas and more distal tubular segments. The procedure with proximal carinas and distal tubular segments, applied to our data, would reduce the median ratio of carinal to tubular particle concentration to about 6:1 .

As well, although necropsy studies of the type performed here clearly reflect patterns of particle deposition, as they agree qualitatively with mathematical and cast studies, they really analyse particle retention-that is, cumulative particle accumulation at a given site. Because analysis of airway mucosa is actually sampling the progressive concentration effect of particles deposited and translocated over time, and because carinal ridges seem, experimentally, to be sites of extremely poor particle clearance ${ }^{911}$ the retained particle load is likely to be greater than one would assume from cast data.

Our findings on concentration distribution differ considerably from those of Schlesinger and Lippmann ${ }^{13}$ who found much greater particle deposition in the upper lobe bronchi of human bronchial casts than in the lower lobe bronchi, a distribution that they noted was similar to that of bronchogenic carcinomas, and also from those of Little et al ${ }^{12}$ who found much greater relative concentrations of ${ }^{210} \mathrm{Po}$ in lower lobe carinas. In the present study there is no evidence for overall differences in particle concentration between upper and lower lobe bronchi, and the ratio of carinal to tubular segments is also the same in both. It should be noted that the data of Little et al ${ }^{12}$ were based on the lungs of smokers, and smoking may well change the relative concentration of particles at carinas.

As we have excluded occupational sources of dust exposure in this study, we presumed that all of the particles we have observed are derived immediately from ambient air, and much of this is a result of natural rock and soil weathering (undoubtedly the source of the most numerous type of particle, crystalline silica). However, it should be remembered that our analytical system does not detect light elements; thus fine carbonaceous particles, which are derived from sources such as vehicle exhaust or power plants, and which are numerous in ambient air, will not be recorded. As well, soluble atmospheric pollutants such as sulphates disappear rapidly in the lung, and are not found in our analyses. It is possible that inclusion of such particles might considerably change the carinal:tubular concentration ratios found. However, most experimental cast studies have used relatively large particles, and all have used insoluble particles, so that comparisons to cast data seem reasonable.

Of particular interest in our study is the notable variability in concentration ratios from case to case. Table 5 shows this in the data on three subjects. In subject $A$, nine of 12 pairs had carinal:tubular ratios $>10$ and six pairs had ratios $>100$. Subject $C$ had only three pairs with ratios $>10$ and three pairs with ratios of $\leqslant 1 \cdot 0$. Subject $B$ was a reasonably "average" subject.

The reason for this variability is unclear. Although airway diameter has been postulated to be the primary determinant of overall airway particle deposition because narrower airways are more likely to lead to contact and retention of a particle on an airway wall, ${ }^{22}$ we were unable to show any correlation of airway size and particle concentration between subjects in our previous study of tubular segments. ${ }^{6}$ Instead, a variation between subjects of several hundredfold in particulate concentration was found over airways of the same generation and diameter, and a similar degree of variation is present in the current set of cases. Particle size, which will affect deposition, also does not seem to explain these variations between subjects, as there is remarkably little variation in particle size from case to case (table 4) and no obvious correlation of particle size and concentration. Simple manual labour, which might lead to much greater tidal volumes, can effectively be ruled out both by occupational history and by the finding that there were no differences in tubular or carinal particle concentrations between men and women. One is left with the likelihood that such long term differences probably reflect variations between subjects in clearance, both in the tubular segments and the carinas. It is possible that subjects who tend to concentrate extremely large numbers of particles at airway carinas are at particular risk of disease, especially that caused by cigarette smoking and that caused by fibrogenic and carcinogenic mineral dusts.

Supported by grants MA6907 and MA7820 from the Medical Research Council of Canada.

1 Dockery DW, Pope CA III. Acute respiratory effects of particulate air pollution. Annu Rev Public Health 1994;15: 107-32.

2 Paoletti L, Eibenschutz L, Cassano AM. Mineral fibres and dust in lungs of subjects living in an urban environment. In: Bignon J, Peto J, Saracci R, eds. Non-occupational exposure to mineral fibres. Lyon: IARC, 1989:354-60.

3 Churg A, Wiggs B. Types, numbers, sizes, and distribution of mineral particles in the lungs of urban male cigarette of mineral particles in the lungs of urb

4 Stettler LE, Growth DH, Platek SF, Burg JR. Particulate 
concentrations in urban lungs. In: Ingram $P$, Shelburne D, Roggli VL, eds. Microprobe analysis in medicine. New York: Hemisphere Press, 1989:133-46.

5 Kalliomaki PL, Taikina-aho O, Paakko P, et al. Smoking and the pulmonary mineral particle burden. In: Bignon J, Peto J, Saracci R, eds. Non-occupational exposure to mineral fibres. Lyon: IARC, 1989:323-9.

6 Churg A, Wright JL, Stevens B. Exogenous mineral particles in the human bronchial mucosa and lung parenchyma. I. Non-smokers in the general population. Exp Lung Res 1990;16:169-75.

7 Churg A, Stevens B. Mineral particles in the human bronchial mucosa. II. Cigarette smokers without emphybronchial mucosa. II. Cigarette smokers

8 Hofmann W, Martonen TB. The significance of enhanced radionuclide deposition at bronchial bifurcations. Ann Occup Hyg 1988;32 (suppl 1):1055-65.

9 Gore DJ, Patrick G. A quantitative study of the penetration of insoluble particles into the tissue of the conducting airways. Ann Occup Hyg 1982;26:149-59.

10 Brody AR, Hill LH, Adkins B, O'Connor RW. Chrysotile asbestos inhalation in rats: deposition pattern and reaction of alveolar epithelium and pulmonary macrophages. Am Rev Respir Dis 1981;123:670-9.

11 Svartengren M, Widtskiold-Olsson K, Philipson $K$ Camner P. Retention of particles on the first bifurcation Camner P. Retention of particles on the first bifurcation and the trachea of rabbits. Bulletin of

12 Little JB, Radord EP, McComb HL Hunt VR Distribution of poloniun-210 in pulmonary tissues of cigarette smokers. N Engl f Med 1965;273:1343-51.

13 Schlesinger B, Lippmann M. Selective particle deposition and bronchogenic carcinoma. Environ Res 1978;15: 424-31.

14 Martell EA. $\alpha$-Radiation at bronchial bifurcations of smokers from indoor exposure to radon progeny. Proc Nat Acad Sci 1983;80:1285-9.

15 Martonen TB, Hofmann W, Lowe JE. Cigarette smoke and lung cancer. Health Physics 1987;52:213-7.

16 Henshaw DL, Few AP, Maharaj R, Shepherd L. Autopsy studies of the microdistribution of $\alpha$-active nuclides in lung tissue. Ann Occup Hyg 1988;32 (suppl 1):1081-93.

17 Cohen BS, et al. Non-uniform particle deposition on tracheobronchial airways: implications for lung dosimetry. Ann Occup Hyg 1988;32(suppl 1):1045-53.

18 Schlesinger RB, Bohning DE, Chan TL, Lippmann $M$ Particle deposition in a hollow cast of the human tracheoParticle deposition in a hollow cast of the hum
bronchial tree. Aerosol Science 1977;8:429-55.

19 Schlesinger RB, Gurman JL, Lippmann M. Particle deposition within bronchial airways: comparison using constan and cyclic inspiratory flows. Ann Occup Hyg 1982;26 47-64.

20 SAS Institute. SASISTAT user's guide, release 6.03. Cary, NC:SAS Institute, 1988

21 Bell KA. Local particle deposition in respiratory airway models. In: DT Shaw, ed. Recent developments in aerosol models. In: Dience. New York: J Wiley, 1978:97-134.

22 Yu CP, Nicolaides $P$, Soong TT. Effect of random airway sizes on aerosol deposition. Am Ind Hyg Assoc $\mathcal{F} 1979$; 40:999-1005.

\section{Correspondence and editorials}

Occupational and Environmental Medicine welcomes correspondence relating to any of the material appearing in the journal. Results from preliminary or small scale studies may also be published in the correspondence column if this seems appropriate. Letters should be not more than 500 words in length and contain a minimum of references. Tables and figures should be kept to an absolute minimum. Letters are accepted on the understanding that they may be subject to editorial revision and shortening.

The journal also publishes editorials which are normally specially commissioned. The Editor welcomes suggestions regarding suitable topics; those wishing to submit an editorial, however, should do so only after discussion with the Editor. 